\title{
CARACTERÍSTICAS DE CARCAÇA E QUALIDADE DA CARNE DE CORDEIROS ALIMENTADOS COM DIFERENTES TEORES DE TORTA DE SOJA EM SUBSTITUIÇÃO AO FARELO DE SOJA
}

\author{
CARCASS CHARACTERISTICS AND MEAT QUALITY OF LAMBS FED \\ WITH DIFFERENT LEVELS OF SOYBEAN CAKE IN REPLACEMENT \\ OF SOYBEAN MEAL
}

\author{
Fernando Augusto Grandis ${ }^{1 *}$ \\ Edson Luis de Azambuja Ribeiro ${ }^{1}$ \\ Ivone Yurika Mizubuti ${ }^{1}$ \\ Valter Harry Bumbieris Junior ${ }^{1}$ \\ Odimári Pricila Pires do Prado ${ }^{1}$ \\ Andréa Pereira Pinto ${ }^{2}$ \\ ${ }^{1}$ Universidade Estadual de Londrina, Londrina, PR, Brasil. \\ ${ }^{2}$ Universidade Federal do Ceará, Fortaleza, CE, Brasil. \\ "Autor para correspondência - fernando_grandis@yahoo.com.br
}

\section{Resumo}

Objetivou-se avaliar a substituição do farelo de soja pela torta de soja sobre as características de carcaça e qualidade da carne de cordeiros Santa Inês. Foram utilizados 29 machos inteiros, com 23,63 $\pm 2,44 \mathrm{~kg}$ de peso vivo, 80 dias de idade, distribuídos de maneira inteiramente casualizada, submetidos a cinco dietas, sendo que as dietas variaram nos teores de substituição do farelo de soja pela torta de soja de $0,25,50,75$ e 100\%. Para cada teor de substituição foram utilizados seis animais, mas no teor de $25 \%$, cinco animais. Foram realizadas avaliações das carcaças e retirou-se o Longissimus dorsi para análises da qualidade da carne. As características da carcaça não foram afetadas pelos diferentes teores de torta de soja. Observou-se efeito quadrático para a força de cisalhamento e efeito linear decrescente para a intensidade de odor, mas não foram observadas diferenças nos demais parâmetros. A substituição do farelo de soja pela torta de soja pode ser realizada sem prejuízo à maioria das características da carcaça e de carne e altos teores de torta de soja na dieta podem resultar em benefícios às qualidades sensoriais da carne de cordeiros recebendo dietas concentradas.

Palavras-chave: análise sensorial; biodiesel; força de cisalhamento; morfometria; Santa Inês.

\begin{abstract}
The objective of this study was to evaluate the replacement of soybean meal by soybean cake on carcass characteristics and meat quality of Santa Ines lambs. Twenty-nine intact males were used, weighing $23.63 \pm 2.44 \mathrm{~kg}$, at 80 days of age, distributed randomly, submitted to five diets, with the diets differing in the levels of substitution of soybean meal by soybean cake $(0,25,50,75$ and $100 \%)$. Each diet was provided to six animals, except the $25 \%$ diet, in which five animals were used. Carcass characteristics were evaluated, and the Longissimus dorsi was removed for meat quality analysis. The different levels of soybean cake did not affect carcass characteristics. Regarding the characteristics of meat, there was a quadratic effect for the shear force and negative linear effect on flavor intensity, but no significant differences on the other parameters were observed. Replacement of soybean meal for soybean cake can be made without affecting most of the carcass and meat characteristics, and
\end{abstract}


high levels of soybean cake in the diet can improve the meat sensorial quality of lambs receiving concentrated diets.

Keywords: biodiesel; morphometry; Santa Ines; sensorial analysis; shear force.

Enviado em: 03 julho de 2014

Aceito em: 25 abril de 2016

\section{Introdução}

A crescente demanda por carne ovina inevitavelmente leva a um aumento da pressão por parte do consumidor à oferta de produtos de alta qualidade ${ }^{(1)}$. Entretanto, no Brasil, ainda se observa baixa qualidade média da carne comercializada, consequência principalmente do abate tardio de animais, resultante do planejamento deficiente e de condições produtivas precárias.

A terminação de cordeiros em confinamento é uma tecnologia que pode proporcionar diversos benefícios à produção de ovinos, como diminuição da idade de abate, otimização do desempenho, padronização das carcaças e aumento no giro de capital. Porém, esses benefícios são acompanhados de aumento significativo nos custos de produção, principalmente devido à alimentação e mão-deobra $^{(2)}$.

O uso de co-produtos da indústria do biodiesel pode ser uma alternativa interessante para a viabilização do confinamento, além de também diminuir potenciais problemas ambientais, causados pela deposição desses produtos no ambiente ${ }^{(3)}$. A soja consiste na oleaginosa mais utilizada na indústria do biodiesel, correspondendo a cerca de $74 \%$ das matérias-primas empregadas ${ }^{(4)}$. Em geral, o óleo é extraído através do método químico, utilizando-se o solvente hexano, em alta temperatura, após a prensagem do grão. Neste método obtém-se o farelo de soja como co-produto, que se caracteriza por possuir um baixo teor de óleo residual.

Como método alternativo de extração do óleo, pode-se realizar a prensagem a frio do grão de soja, do qual se obtém a torta de soja. Apesar de o processo não ser tão eficiente em larga escala, torna-se uma alternativa interessante em escala familiar, visto que apenas uma prensa simples é requerida no processamento do grão ${ }^{(5)}$.

$\mathrm{O}$ alto valor energético das tortas residuais, consequente principalmente do extrato etéreo residual, pode proporcionar incrementos nas características de carcaça e qualidade de carne, como no rendimento na maciez e marmoreio e, portanto, nos parâmetros sensoriais ${ }^{(6,7)}$. Desta maneira, tornase importante a avaliação das características qualitativas e quantitativas da carcaça e da carne na avaliação de alimentos alternativos, visando à otimização dos lucros na produção bem como a oferta de produtos que atendam à crescente demanda do exigente mercado consumidor ${ }^{(8)}$.

Assim, objetivou-se com este trabalho avaliar o efeito da substituição do farelo de soja pela torta de soja sobre as características de carcaça e qualidade da carne de cordeiros Santa Inês terminados em confinamento.

\section{Material e Métodos}

O experimento foi conduzido de acordo com as normas éticas e aprovado pelo Comitê de Ética em Experimentação Animal, da Universidade Estadual de Londrina (CEEA-UEL), ofício circular $n^{\circ}$ $123 / 2010$.

O experimento foi realizado na Fazenda Escola e Departamento de Zootecnia da Universidade Estadual de Londrina. Foram utilizados 29 animais da raça Santa Inês, machos inteiros, com 80 dias de idade 
e peso inicial de $23,63 \pm 2,44 \mathrm{~kg}$, que permaneceram confinados durante o período de setembro a outubro de 2012 (47 dias), precedidos de 14 dias de adaptação às condições experimentais. No início do experimento, os animais foram pesados, identificados, vacinados e vermifugados e distribuídos aleatoriamente em duplas, em baias de $2 \mathrm{~m}^{2}$, em aprisco coberto, com piso ripado, providas de comedouro e bebedouro.

O delineamento empregado foi inteiramente casualizado, com os animais sendo as repetições, e cada um dos cinco tratamentos sendo composto por seis animais. Os tratamentos foram: sem torta de soja, $25,50,75$ e $100 \%$ de substituição do farelo de soja pela torta de soja. Durante o período experimental, um cordeiro do tratamento de $25 \%$ foi removido do experimento, devido a problemas sanitários.

As rações foram formuladas para atender às exigências nutricionais segundo o $\operatorname{NRC}^{(9)}$ (Tabela 1), utilizando-se a categoria de cordeiros desmamados precocemente, com potencial moderado de ganho, $20 \mathrm{~kg}$ de peso vivo, ganho de peso diário de $250 \mathrm{~g}$. A relação volumoso:concentrado empregada foi de 35:65. A determinação de matéria seca (MS), proteína bruta (PB), extrato etéreo (EE) e cinzas das rações foi realizada segundo Silva e Queiroz ${ }^{(10)}$ e as determinações de fibra em detergente neutro (FND) e fibra em detergente ácido (FDA), segundo Detmann et al.(11). Para a estimativa dos nutrientes digestíveis totais (NDT), utilizaram-se as equações propostas por Kearl ${ }^{(12)}$.

Ao final do período experimental, realizou-se a pesagem dos animais, precedida de um período de 16 horas de jejum de sólidos, para a obtenção do peso vivo final. Após a pesagem, os animais se alimentaram normalmente até a retirada do alimento, programada de forma a garantir 16 horas de jejum de sólidos pré-abate. Neste intervalo de tempo, os animais foram transportados ao frigorífico com inspeção municipal, distando $40 \mathrm{~km}$, onde permaneceram em baia de espera, provida de água e sombra.

O abate foi realizado seguindo as normas de abate humanitário, com os animais sendo insensibilizados por eletronarcose, seguido de sangria, esfola e evisceração. Em seguida, as carcaças foram identificadas, lavadas, pesadas e resfriadas em câmaras frias a $2{ }^{\circ} \mathrm{C}$.

As carcaças foram pesadas logo após o abate, para obtenção do peso da carcaça quente (PCQ). Após 24 horas de resfriamento a $2{ }^{\circ} \mathrm{C}$, as carcaças foram novamente pesadas para a obtenção do peso da carcaça fria (PCF). Com estes dados foram calculados os rendimentos de carcaça quente (RCQ) e fria $(\mathrm{RCF})$ e a perda no resfriamento (PR) sendo RCQ e RCF calculados pela razão entre estes e o peso vivo final (PF), segundo Osório e Osório ${ }^{(13)}$.

No momento do abate foram coletadas as vísceras dos animais e, posteriormente, foram separados os estômagos e os intestinos e então pesados cheios e vazios, para a obtenção do peso corporal vazio $(\mathrm{PCV})$ e rendimento verdadeiro $(\mathrm{RV})$, sendo $\mathrm{PCV}=\mathrm{PF}$ - conteúdo gastrintestinal e $\mathrm{RV}=((\mathrm{PCQ} /$ $\left.\mathrm{PCV})^{*} 100\right)$.

Foram realizadas as avaliações de conformação (valores de 1-côncavo a 6-convexo), acabamento (valores de 1-gordura de cobertura ausente a 5-gordura de cobertura abundante) e gordura estriada do flanco, utilizando-se padrões fotográficos ${ }^{(13)}$.

As medidas de comprimento de carcaça e profundidade torácica, comprimento, perímetro e profundidade de perna e braço foram feitas segundo a metodologia proposta por Osório e Osório ${ }^{(13)}$. Para o cálculo de índice de compacidade da carcaça (ICC), dividiu-se PCF/comprimento interno da carcaça.

As meias carcaças esquerdas foram seccionadas na altura da $12^{\mathrm{a}}$ costela para avaliação da área de olho de lombo, espessura de gordura, profundidade e largura do músculo Longissimus dorsi. O marmoreio foi avaliado subjetivamente utilizando-se padrões fotográficos propostos pela American Meat Science Association $^{(14)}$, em que são atribuídas subjetivamente, pela mesma pessoa, notas de 1 a 10 (1-traços de marmoreio e 10-marmoreio abundante).

As carcaças foram divididas em paleta, pernil, pescoço e o costilhar, subdivididas na junção entre a coluna vertebral e as costelas. As porções foram pesadas para se verificar a porcentagem dos cortes na carcaça. 
Tabela 1. Proporção dos ingredientes e composição nutricional das dietas experimentais

\begin{tabular}{lccccc}
\hline \multirow{2}{*}{ Ingredientes, $\mathbf{g} / \mathbf{k g}$ de MS } & \multicolumn{5}{c}{ Teores de torta de soja (\%) } \\
\cline { 2 - 6 } & $\mathbf{0}$ & $\mathbf{2 5}$ & $\mathbf{5 0}$ & $\mathbf{7 5}$ & $\mathbf{1 0 0}$ \\
\hline Silagem Sorgo & 350,00 & 350,00 & 350,00 & 350,00 & 350,00 \\
Milho triturado & 392,40 & 390,70 & 389,00 & 387,20 & 385,50 \\
Farelo de Soja & 242,60 & 183,20 & 123,00 & 61,90 & 0,00 \\
Torta de Soja & 0,00 & 61,10 & 123,00 & 185,80 & 249,50 \\
Calcário calcítico $^{\text {Mistura Mineral }}{ }^{1}$ & 10,00 & 10,00 & 10,00 & 10,00 & 10,00 \\
\hline
\end{tabular}

Composição nutricional

\begin{tabular}{lccccc}
\hline Matéria seca (g/kg MN) & 679,70 & 679,00 & 678,40 & 677,60 & 677,0 \\
Matéria mineral (g/kg MS) & 39,5 & 39,2 & 38,9 & 38,5 & 38,2 \\
Proteína bruta (g/kg MS) & 178,9 & 178,6 & 178,4 & 178,1 & 177,9 \\
Extrato etéreo (g/kg MS) & 23,7 & 27,6 & 31,4 & 35,4 & 39,4 \\
Fibra detergente neutro (g/kg MS) & 334,9 & 334,10 & 333,30 & 332,40 & 331,60 \\
Fibra detergente ácido (g/kg MS) & 145,40 & 145,20 & 144,90 & 144,70 & 144,50 \\
Nutrientes digestíveis totais ${ }^{2}$ (g/kg MS) & 729,80 & 733,90 & 738,10 & 742,20 & 746,60 \\
\hline
\end{tabular}

'Mistura Mineral: Cálcio 128,00 g; Enxofre 10,00 g; Fósforo 60,00 g; Magnésio 6.000,00 mg; Sódio 152,00 mg; Cobalto $50,00 \mathrm{mg}$; Ferro 1.400,00 mg; Iodo 74,00 mg; Manganês 1.800,00 mg; Selênio 15,00 mg; Zinco $2.730 \mathrm{mg}$; Flúor $500,00 \mathrm{mg}$.

'Segundo Kear1(12).

A paleta esquerda foi levada ao laboratório e congelada para posterior realização de dissecação, para se obter a proporção de osso, músculo e gordura da carcaça, segundo a metodologia de Fisher e De Boer $^{(15)}$.

As porções da coluna vertebral foram encaminhadas ao laboratório, onde realizou-se a desossa do costilhar, liberando o músculo Longissimus dorsi, que foi então subdividido em partes para a realização das seguintes análises: três porções $(3 \mathrm{~cm}$ de espessura cada) para força de cisalhamento; uma porção ( $2 \mathrm{~cm}$ de espessura) para se realizarem as medidas de cor, $\mathrm{pH}$, marmoreio e perda de água por pressão (PAP); duas porções ( $3 \mathrm{~cm}$ de espessura) para a análise sensorial; e uma porção para análise da composição centesimal ( $2 \mathrm{~cm}$ de espessura).

A força de cisalhamento foi medida com o auxílio do aparelho texturômetro Brookfield $®$ CT3 Texture Analyzer com a probe blade shear $3 \mathrm{~mm}$. Para a obtenção das amostras, foi utilizado um amostrador de aço de forma cilíndrica. As amostras foram aquecidas até a temperatura interna de $71{ }^{\circ} \mathrm{C}$, sendo utilizadas duas porções por animal. De cada porção, três subamostras foram retiradas $(1,25 \times 2,5 \mathrm{~cm})$, totalizando seis leituras por animal, seguindo a metodologia de Whipple et al. ${ }^{(16)}$.

A cor foi avaliada por meio do aparelho colorímetro portátil Minolta ${ }^{\circledR}$ CR-10 para avaliação dos componentes L* (luminosidade), a* (componente vermelho-verde) e b* (componente amarelo-azul) que foram expressos no sistema de cor CIELAB. Com esses valores, foi feito o cálculo do ângulo de tonalidade $\left(h^{*}\right)$ pela equação $h^{*}=\tan ^{-1}\left(b^{*} / a^{*}\right)$, e o índice de saturação, ou croma, $\left(c^{*}\right)$ a partir da equação $\mathrm{c}^{*}=\left(\mathrm{a} * 2+\mathrm{b}^{*} 2\right) 0,5$.

A PAP foi realizada pelo método de pressão em papel filtro, proposto por Barbut ${ }^{(17)}$. O pH foi medido utilizando-se um potenciômetro portátil da marca Testo ${ }^{\circledR} 205$. As análise da composição centesimal do músculo foram realizadas segundo a metodologia da $\mathrm{AOAC} \mathrm{C}^{(18)}$, determinando-se MS, cinzas, $\mathrm{PB}$ e gordura.

A análise sensorial foi realizada por meio de uma escala estruturada conforme a metodologia 
proposta pela $\mathrm{ABNT}^{(19)}$. Foram utilizados oito provadores treinados para avaliarem intensidade de odor (1-nenhum a 5-extremamente intenso), suculência (1-nenhuma a 5-alta), maciez (1-muito dura a 7-muito macia) e aceitabilidade global (1-extremamente inaceitável a 9-extremamente aceitável).

Cada provador recebeu uma ficha de avaliação sensorial e 3 amostras (dos tratamentos de 0, 50 e $100 \%$ de substituição). No intervalo entre as amostras dos diferentes tratamentos, os provadores realizaram limpeza e rinsagem da boca com água, bolacha água e sal e limpeza do olfato com pó de café. Não foram utilizadas amostras dos tratamentos de 25 e $75 \%$ de substituição para evitar a saturação dos provadores.

Os dados obtidos foram submetidos a análise de variância e regressão polinomial, no caso de significância ao nível de 5\% utilizando-se o pacote estatístico SAS (versão 8.2).

\section{Resultados e Discussão}

Não foi encontrado efeito $(\mathrm{P}>0,05)$ da substituição do farelo de soja pela torta de soja nos parâmetros de PF, PCQ e PCF, RCQ, RCF e RV, PR, conformação, acabamento, gordura estriada do flanco e pesos e conteúdo do trato gastrintestinal (Tabela 2).

O RCQ médio foi de $46,95 \%$, o RCF foi de 45,05 \% e o RV 52,70 \%. Estes valores estão dentro da faixa esperada para animais machos inteiros, da raça Santa Inês, terminados em confinamento. Apesar de os valores de rendimentos de carcaça poderem ser afetados pela composição química da dieta, no presente trabalho, isto não ocorreu, o que pode ser considerado positivo, pois substituindo o principal ingrediente proteico usado na alimentação animal (o farelo de soja) por uma fonte de obtenção mais simples (a torta de soja), não foram verificados prejuízos nos rendimentos de carcaça.

Cartaxo et al. ${ }^{(20)}$, trabalhando com cordeiros Santa Inês em confinamento, abatidos aos $31,42 \mathrm{~kg}$ de peso vivo, obtiveram valores de RCQ de $46,82 \%$ e RCF de $45,95 \%$, valores muito próximos aos do presente estudo. Da mesma forma, Urano et al. ${ }^{(21)}$ tiveram valores de RCQ e RCF de 48,87 e 47,7 \%, respectivamente, para animais Santa Inês confinados recebendo soja em grão na ração.

Para o RV, Cartaxo et al. ${ }^{(20)}$ verificaram valor médio de 50,10\%, para animais abatidos aos $31,42 \mathrm{~kg}$ de peso vivo. Macedo et al. ${ }^{(22)}$ econtraram valor de $57,83 \%$, testando diferentes teores de semente de girassol na dieta de cordeiros Suffolk mestiços em creep feeding, mantidos com as mães até o peso de abate $(28 \mathrm{~kg})$. O valor alcançado por Macedo et al. ${ }^{(22)}$ foi bem superior ao presente estudo e ao estudo acima citado, provavelmente por diferenças no tipo genético dos animais, influenciando na capacidade física ruminal e, consequentemente, no esvaziamento do trato gastrintestinal (TGI) no jejum.

A PR consiste na perda de umidade da carcaça na câmara fria e nas reações químicas que ocorrem no músculo no pós-abate, durante o processo de resfriamento. Silva Sobrinho et al ${ }^{(23)}$ relataram que essas perdas são maiores em carcaças com menor espessura de gordura subcutânea. No presente trabalho, o valor médio para os animais que receberam as diferentes dietas foi de $4,07 \%$, estando bem próximo ao citado por Furusho-Garcia et al. ${ }^{(24)}$, de 4,3 \%, para animais Santa Inês confinados e abatidos aos $35 \mathrm{~kg}$ de peso vivo.

Em relação às medidas subjetivas (conformação, acabamento e gordura estriada do flanco), os valores médios encontrados foram 2,62, 2,59 e 2,07, respectivamente. Segundo o padrão utilizado, as carcaças podem ser caracterizadas como côncavas a retilíneas, com médio a bom desenvolvimento muscular e com leve a médio acabamento, com porções de músculos aparentes.

A taxa de esvaziamento do TGI está diretamente relacionada com a porcentagem de fibra na dieta, sendo que animais alimentados com maiores proporções de concentrado apresentam esvaziamento mais rápido, uma vez que a taxa de passagem é mais rápida nessas condições ${ }^{(25)}$. Portanto, como a relação volumoso:concentrado e o teor de FDN foram semelhantes em todos as dietas, não foram observadas diferenças nos valores de TGI cheio e vazio e, consequentemente, também não foi 
encontrada diferença $(\mathrm{P}>0,05)$ no RV, visto que o PCQ foi semelhante entre as dietas.

A substituição do farelo de soja pela torta de soja, nos diferentes teores, não afetou $(\mathrm{P}>0,05)$ os parâmetros morfométricos. Também não influenciou o ICC, porcentagem de cortes cárneos e composição tecidual da paleta (Tabela 3).

Tabela 2. Características de carcaça de cordeiros confinados recebendo dietas com diferentes teores de torta de soja em substituição ao farelo de soja

\begin{tabular}{|c|c|c|c|c|c|c|c|}
\hline \multirow{2}{*}{ Características } & \multicolumn{5}{|c|}{ Teores de torta de soja (\%) } & \multirow[b]{2}{*}{$\mathbf{R}^{1}$} & \multirow[b]{2}{*}{$\mathrm{CV}^{2}(\%)$} \\
\hline & $\mathbf{0}$ & 25 & 50 & 75 & 100 & & \\
\hline Peso vivo final (kg) & 39,12 & 38,90 & 39,38 & 37,73 & 37,35 & $\hat{\mathrm{Y}}=38,48$ & 9,33 \\
\hline Peso corporal vazio $(\mathrm{kg})$ & 35,10 & 34,74 & 35,09 & 33,59 & 33,02 & $\hat{\mathrm{Y}}=34,29$ & 9,56 \\
\hline Peso carcaça quente $(\mathrm{kg})$ & 18,35 & 18,48 & 18,7 & 17,67 & 17,33 & $\hat{\mathrm{Y}}=18,09$ & 11,32 \\
\hline Peso carcaça fria (kg) & 17,68 & 17,7 & 17,94 & 16,93 & 16,58 & $\hat{\mathrm{Y}}=17,36$ & 11,22 \\
\hline $\mathrm{RCQ}^{3}(\mathrm{Kg} / 100 \mathrm{~kg}$ peso vivo $)$ & 46,93 & 47,44 & 47,40 & 46,79 & 46,29 & $\hat{\mathrm{Y}}=46,95$ & 3,79 \\
\hline $\mathrm{RCF}^{4}(\mathrm{Kg} / 100 \mathrm{~kg}$ peso vivo $)$ & 45,23 & 45,43 & 45,50 & 44,87 & 44,27 & $\hat{\mathrm{Y}}=45,05$ & 3,79 \\
\hline $\mathrm{RV}^{5}(\mathrm{Kg} / 100 \mathrm{~kg} \mathrm{PCV})$ & 52,28 & 53,15 & 53,19 & 52,55 & 52,42 & $\hat{\mathrm{Y}}=52,70$ & 3,52 \\
\hline $\mathrm{PR}^{6}(\mathrm{Kg} / 100 \mathrm{~kg}$ peso vivo $)$ & 3,60 & 4,25 & 4,01 & 4,10 & 4,38 & $\hat{\mathrm{Y}}=4,06$ & 16,99 \\
\hline Conformação ${ }^{7}$ & 2,58 & 2,60 & 2,67 & 2,58 & 2,67 & $\hat{\mathrm{Y}}=2,62$ & 14,11 \\
\hline Acabamento $^{8}$ & 2,92 & 2,80 & 2,67 & 2,25 & 2,33 & $\hat{\mathrm{Y}}=2,59$ & 16,83 \\
\hline Gordura estriada do flanco ${ }^{9}$ & 2,08 & 2,30 & 2,25 & 2,00 & 1,75 & $\hat{\mathrm{Y}}=2,07$ & 25,65 \\
\hline Trato Gastrintestinal vazio $(\mathrm{Kg})$ & 3,54 & 3,29 & 3,62 & 3,54 & 3,42 & $\hat{\mathrm{Y}}=3,49$ & 13,03 \\
\hline Trato Gastrintestinal cheio $(\mathrm{Kg})$ & 7,55 & 7,44 & 7,91 & 7,68 & 7,76 & $\hat{\mathrm{Y}}=7,68$ & 11,82 \\
\hline
\end{tabular}

${ }^{1}$ Regressão; ${ }^{2}$ Coefíciente de variação; ${ }^{3}$ Rendimento de carcaça quente; ${ }^{4}$ Rendimento de carcaça fria; ${ }^{5}$ Rendimento verdadeiro; ${ }^{6} \mathrm{Perda}$ ao resfriamento; 7 Valores de 1 -côncava a 6 -convexa; ${ }^{8}$ valores de 1 -gordura de cobertura ausente a 5 gordura de cobertura abundante; ${ }^{9}$ Valores de 1-baixo a 3-alto. $\mathrm{P}>0,05$.

Tabela 3. Parâmetros morfométricos, peso dos cortes e composição tecidual da paleta de cordeiros recebendo dietas com diferentes teores de substituição do farelo de soja pela torta de soja

\begin{tabular}{|c|c|c|c|c|c|c|c|}
\hline \multirow{2}{*}{ Discriminação } & \multicolumn{5}{|c|}{ Teores de torta de soja (\%) } & \multirow[b]{2}{*}{$\mathbf{R}^{1}$} & \multirow[b]{2}{*}{$\mathrm{CV}^{2}(\%)$} \\
\hline & $\mathbf{0}$ & 25 & 50 & 75 & 100 & & \\
\hline Comprimento carcaça $(\mathrm{cm})$ & 61,83 & 60,40 & 62,67 & 61,00 & 61,50 & $\hat{\mathrm{Y}}=61,52$ & 3,46 \\
\hline Profundidade torácica $(\mathrm{cm})$ & 25,17 & 25,00 & 25,50 & 25,33 & 25,50 & $\hat{\mathrm{Y}}=25,31$ & 4,04 \\
\hline Comprimento pernil $(\mathrm{cm})$ & 41,75 & 40,20 & 41,75 & 42,50 & 41,00 & $\hat{\mathrm{Y}}=41,48$ & 4,55 \\
\hline Perímetro pernil $(\mathrm{cm})$ & 40,67 & 42,70 & 40,75 & 40,67 & 39,25 & $\hat{\mathrm{Y}}=40,74$ & 5,65 \\
\hline Profundidade pernil $(\mathrm{cm})$ & 9,50 & 10,30 & 9,50 & 9,42 & 9,17 & $\hat{\mathrm{Y}}=9,55$ & 8,64 \\
\hline Comprimento braço $(\mathrm{cm})$ & 20,25 & 19,60 & 20,25 & 20,50 & 20,42 & $\hat{\mathrm{Y}}=20,22$ & 4,47 \\
\hline Perímetro braço $(\mathrm{cm})$ & 17,67 & 18,40 & 17,92 & 17,58 & 17,67 & $\hat{\mathrm{Y}}=17,83$ & 4,48 \\
\hline Profundidade braço $(\mathrm{cm})$ & 5,42 & 5,80 & 5,50 & 5,42 & 5,50 & $\hat{\mathrm{Y}}=5,52$ & 9,22 \\
\hline Compacidade carcaça $(\mathrm{kg} / \mathrm{cm})$ & 0,29 & 0,29 & 0,28 & 0,28 & 0,27 & $\hat{\mathrm{Y}}=0,28$ & 9,82 \\
\hline Paleta $(\mathrm{kg} / 100 \mathrm{~kg}$ carcaça) & 19,62 & 20,16 & 19,72 & 20,45 & 19,62 & $\hat{\mathrm{Y}}=19,91$ & 4,50 \\
\hline Pernil (kg/100 kg carcaça) & 33,08 & 33,63 & 32,80 & 33,79 & 33,14 & $\hat{\mathrm{Y}}=33,29$ & 3,37 \\
\hline Lombo (kg/100 kg carcaça) & 20,30 & 20,38 & 21,14 & 20,42 & 20,23 & $\hat{\mathrm{Y}}=20,49$ & 6,01 \\
\hline Costela (kg/100 kg carcaça) & 19,92 & 19,29 & 19,97 & 18,29 & 19,84 & $\hat{\mathrm{Y}}=19,46$ & 7,51 \\
\hline Pescoço $(\mathrm{kg} / 100 \mathrm{~kg}$ carcaça $)$ & 7,08 & 6,53 & 6,36 & 7,04 & 7,17 & $\hat{\mathrm{Y}}=6,84$ & 12,55 \\
\hline Osso (kg/100 kg paleta) & 23,71 & 21,65 & 23,62 & 21,84 & 23,64 & $\hat{\mathrm{Y}}=22,93$ & 9,54 \\
\hline Músculo (kg/100 kg paleta) & 64,89 & 65,00 & 62,62 & 64,33 & 62,89 & $\hat{\mathrm{Y}}=63,91$ & 4,30 \\
\hline Gordura ( $\mathrm{kg} / 100 \mathrm{~kg}$ paleta) & 13,36 & 13,34 & 13,76 & 13,82 & 13,47 & $\hat{\mathrm{Y}}=13,15$ & 18,68 \\
\hline
\end{tabular}

${ }^{1}$ Regressão; ${ }^{2}$ Coeficiente de Variação. $P>0,05$. 
Em relação às medidas de comprimento da carcaça, profundidade torácica, comprimento, profundidade e perímetro do pernil e do braço, no geral, observa-se maior influência genética, de idade e do peso de abate do que efeitos nutricionais dentro de cada raça. Nesse sentido, Fernandes Junior et al. ${ }^{(26)}$, testando diferentes teores de torta de girassol na terminação de cordeiros Santa Inês confinados também não encontraram efeito significativo sobre a morfometria da carcaça, em nenhum dos parâmetros, e os valores médios observados neste trabalho foram muito próximos aos verificados pelos autores.

Os principais cortes comerciais da carcaça ovina são paleta, pernil, lombo, costelas e pescoço ${ }^{(27)}$. As porcentagens médias dos cortes comerciais encontradas foram: 19,91\% paleta, 33,29\% pernil, $20,49 \%$ lombo, $19,46 \%$ costela e $6,84 \%$ pescoço. Os valores se assemelham àqueles encontrados por Cartaxo et al. ${ }^{(20)}$, que foram de, respectivamente, $18,60 \%, 30,57 \%, 12,53 \%, 26,41 \%$ e $7,43 \%$. A maior diferença entre os trabalhos ocorreu entre a porcentagem de lombo e costela, porém, quando expresso como costilhar, somando-se o lombo e a costela, os valores foram mais próximos, 39,95\% no presente trabalho e $38,94 \%$ no trabalho de Cartaxo et al. ${ }^{(20)}$.

Ribeiro et al. ${ }^{(28)}$, comparando as características de carcaça de 3 grupos genéticos (Texel x Hampshire Down, Texel x Ille de France e Texel x Suffolk), encontraram os seguintes valores para porcentagem de paleta, pernil, costilhar e pescoço: $22,09,35,49,36,21$ e $6,20 \%$, para o primeiro grupo, 19,61, $36,70,36,23$ e $7,45 \%$ para o segundo grupo e $21,76,35,87,36,06$ e 6,30 para o terceiro grupo, respectivamente, sem encontrar diferença significativa entre os grupos genéticos. Mesmo em se tratando de quatro grupos distintos, na comparação entre os dois trabalhos, os valores encontrados para os rendimentos de cortes são bem semelhantes.

Esses resultados estão de acordo com a teoria da harmonia anatômica, citada por Boccard \& Dummont ${ }^{(29)}$, que enuncia que, em carcaças de pesos e quantidades de gorduras similares, quase todas as regiões corporais se encontram em proporções semelhantes, independente dos genótipos. No trabalho de Ribeiro et al. ${ }^{(28)}$, os animais foram abatidos com pesos próximos a $40 \mathrm{~kg}$, valor similar ao do presente estudo, de $38,58 \mathrm{~kg}$ de peso médio ao abate.

O ICC mostra a relação entre o peso e o comprimento da carcaça, ou seja, mede a quantidade de tecido depositado por unidade de comprimento. Este índice é uma medida indireta da conformação, utilizado para avaliar a produção de músculo de animais com peso vivo semelhante ${ }^{(30)}$. O valor médio de ICC no presente estudo foi de 0,28 , valor superior ao encontrado por Zundt et al. ${ }^{(31)}$ utilizando a mesma raça $(0,24)$. Esta diferença provavelmente é resultado dos diferentes pesos de abate entre ambos estudos, em que os autores abateram os animais com média de $29,4 \mathrm{~kg}$, ao passo que neste estudo o peso médio de abate foi de $38,58 \mathrm{~kg}$. O mais tardio desenvolvimento dos tecidos muscular e adiposo em relação ao crescimento ósseo ${ }^{(32)}$ provavelmente contribuiu para esta diferença, com os animais mais pesados já apresentando um maior desenvolvimento muscular e deposição de tecido adiposo, resultando em maior ICC.

A composição tecidual é variável de acordo com genótipo, sexo, alimentação, peso e idade de abate. Para a obtenção da composição tecidual, como a dissecação completa da carcaça é onerosa, utilizou-se a paleta que, segundo Fisher e De Boer ${ }^{(15)}$, possui alta correlação com a composição tecidual corporal.

A composição tecidual encontrada na paleta foi de $22,89 \%$ de osso, $63,95 \%$ de músculo e $13,15 \%$ de gordura, valores semelhantes aos 21,50,66,91 e 11,58 \%, respectivamente, encontrados por Garcia et al. ${ }^{(33)}$, para a composição tecidual de cordeiros Suffolk abatidos aos $31 \mathrm{~kg}$ de peso vivo. Santos et al. ${ }^{(34)}$ observaram valores de $25,13 \%$ de osso, $68,47 \%$ de músculo e $6,39 \%$ de gordura para ovinos Santa Inês submetidos à suplementação de $1,5 \%$ do peso vivo, em pastagem nativa, abatidos aos 30 $\mathrm{kg}$ de peso vivo.

Os diferentes teores de torta de soja não influenciaram $(\mathrm{P}>0,05)$ os parâmetros do músculo Longissimus dorsi, à exceção da força de cisalhamento, para a qual foi observado efeito quadrático $(\mathrm{P}<0,05)$ (Tabela 4).

A mensuração da área de olho de lombo (AOL) é de grande utilidade na predição da quantidade de músculo na carcaça, uma vez que este índice é correlacionado com a porcentagem de carne na carcaça. De maneira similar, a medida da espessura de gordura, tomada acima do músculo Longissimus dorsi, 
também possui boa correlação com a composição de gordura da carcaça ${ }^{(35)}$.

No presente trabalho, os valores médios encontrados para a AOL foram de $14,60 \mathrm{~cm}^{2}$ e 2,53 mm para a gordura de cobertura, resultados próximos àqueles encontrados por Araújo et al. ${ }^{(36)}$, de $14,25 \mathrm{~cm}^{2} \mathrm{e}$ $3,33 \mathrm{~mm}$, respectivamente, para animais Santa Inês confinados, com relação volumoso:concentrado de 30:70, abatidos aos $40 \mathrm{~kg}$ de peso vivo. Para profundidade e largura, os valores médios obtidos foram 5,29 e 3,33 cm, enquanto Araújo et al. ${ }^{(36)}$ obtiveram 5,75 e 3,25 cm, respectivamente, resultados muito parecidos, consequentes provavelmente da similaridade entre a composição das dietas, pesos de abate e grupos genéticos.

Tabela 4. Parâmetros do músculo Longissimus dorsi da carcaça de cordeiros alimentados com dietas contendo diferentes teores de torta de soja em substituição ao farelo de soja

\begin{tabular}{|c|c|c|c|c|c|c|c|}
\hline \multirow{2}{*}{ Parâmetro } & \multicolumn{5}{|c|}{ Teores de torta de soja (\%) } & \multirow[b]{2}{*}{$\mathbf{R}^{\mathbf{l}}$} & \multirow[b]{2}{*}{$\mathrm{CV}^{2}(\%)$} \\
\hline & 0 & 25 & 50 & 75 & 100 & & \\
\hline Profundidade (mm) & 51,57 & 54,95 & 52,78 & 52,95 & 52,72 & $\hat{\mathrm{Y}}=52,93$ & 7,20 \\
\hline Largura (mm) & 35,84 & 29,98 & 34,95 & 32,23 & 33,38 & $\hat{\mathrm{Y}}=33,39$ & 12,01 \\
\hline Área olho de lombo $\left(\mathrm{cm}^{2}\right)$ & 14,96 & 14,40 & 15,46 & 13,96 & 14,21 & $\hat{\mathrm{Y}}=14,60$ & 13,94 \\
\hline Espessura de gordura (mm) & 3,15 & 2,25 & 2,44 & 2,17 & 2,58 & $\hat{\mathrm{Y}}=2,53$ & 45,39 \\
\hline Marmoreio $^{3}$ & 3,67 & 3,60 & 3,17 & 3,17 & 3,83 & $\hat{\mathrm{Y}}=3,48$ & 35,67 \\
\hline $\mathrm{pH}$ & 5,63 & 5,57 & 5,52 & 5,57 & 5,52 & $\hat{\mathrm{Y}}=5,56$ & 1,80 \\
\hline $\mathrm{PAP}^{4}(\mathrm{~g} / 100 \mathrm{~g})$ & 15,79 & 16,75 & 21,19 & 21,11 & 21,75 & $\hat{\mathrm{Y}}=19,41$ & 23,43 \\
\hline $\operatorname{PAD}^{5}(\mathrm{~g} / 100 \mathrm{~g})$ & 4,75 & 3,62 & 4,95 & 7,27 & 5,01 & $\hat{\mathrm{Y}}=5,17$ & 51,86 \\
\hline $\operatorname{PAC}^{6}(\mathrm{~g} / 100 \mathrm{~g})$ & 22,15 & 22,83 & 22,68 & 23,61 & 25,14 & $\hat{\mathrm{Y}}=23,30$ & 14,38 \\
\hline $\mathrm{FC}^{7}(\mathrm{kgf} / \mathrm{cm})$ & 2,79 & 3,53 & 3,40 & 3,09 & 3,05 & $\hat{\mathrm{Y}}^{13}$ & 12,74 \\
\hline $\mathrm{L}^{* 8}$ & 40,43 & 40,22 & 40,53 & 39,93 & 40,50 & $\hat{\mathrm{Y}}=40,33$ & 5,75 \\
\hline$a^{* 9}$ & 14,70 & 15,36 & 14,98 & 15,17 & 15,30 & $\hat{\mathrm{Y}}=15,09$ & 7,27 \\
\hline $\mathrm{b} * 10$ & 9,88 & 10,80 & 9,98 & 10,37 & 10,90 & $\hat{\mathrm{Y}}=10,37$ & 13,40 \\
\hline$c^{* 11}$ & 17,75 & 18,77 & 18,02 & 18,40 & 18,79 & $\hat{\mathrm{Y}}=18,33$ & 8,18 \\
\hline $\mathrm{h} * 012$ & 33,74 & 34,90 & 33,57 & 34,34 & 35,34 & $\hat{\mathrm{Y}}=34,35$ & 8,45 \\
\hline
\end{tabular}

${ }^{1}$ Regressão; ${ }^{2}$ Coeficiente de variação; ${ }^{3}$ Escala de 1 -traços de marmoreio a 10 -marmoreio abundante; ${ }^{4}$ Perda de água por pressão; ${ }^{5} \mathrm{Perda}$ de água no descongelamento; ${ }^{6} \mathrm{Perda}$ de água na cocção; ${ }^{7}$ Força de cisalhamento; ${ }^{8} \mathrm{Luminosidade;}$ ${ }^{9}$ Componente verde-vermelho; ${ }^{10} \mathrm{Componente} \mathrm{azul-amarelo;}{ }^{11} \mathrm{Croma}$ (saturação); ${ }^{12}$ Tonalidade; ${ }^{13} \hat{\mathrm{Y}}=2,89+0,01973 \mathrm{x}-$ $0,00019 x^{2}, R^{2}=0,64(P<0,05)$.

O marmoreio médio apresentado pelos animais foi de 3,48 (escala de 1 a 10), sendo semelhantes entre as diferentes dietas. Segundo Rosa et al. ${ }^{(32)}$, a deposição do tecido adiposo é a mais tardia no animal. Como, no geral, a raça Santa Inês possui um desenvolvimento mais tardio em relação às raças especializadas para produção de carne, observou-se baixo marmoreio nos animais, considerando-se o peso de abate de $38,48 \mathrm{~kg}$.

Cartaxo et al. ${ }^{(37)}$ encontraram valor de marmoreio médio de 2,55 para animais abatidos aos 36,61 $\mathrm{Kg}$ de peso corporal e Sousa et al. ${ }^{(38)}$ de 3,26, ambos para animais da raça Santa Inês em confinamento, submetidos a dietas com composição química similar à do presente trabalho. Vale ressaltar que os animais no estudo de Sousa et al. ${ }^{(38)}$ foram abatidos aos $54 \mathrm{Kg}$ de peso corporal. Assim, deve-se atentar à possível inviabilidade do abate tardio de animais Santa Inês, visto que a gordura de marmoreio, que é interessante para o consumidor sob o ponto de vista sensorial, foi similar quando se avaliaram animais abatidos aos 38,48 $\mathrm{Kg}$ e $54 \mathrm{Kg}$. No abate mais tardio, deve-se atentar principalmente à conversão alimentar, que tende a piorar com o crescimento dos animais, bem como ao odor sexual presente na carne ovina em animais inteiros, maduros sexualmente.

$\mathrm{O}$ pH é o principal indicador da qualidade final da carne, pois exerce significativa influência sobre 
os demais parâmetros. Em ovinos, os valores observados variam na faixa de 5,5 a 5,8, sendo estes influenciados por diversos fatores, como sexo do animal, peso de abate, sistema de produção, genética e manejo pré-abate ${ }^{(23)}$.

$\mathrm{O}$ pH médio entre todos os animais foi de 5,56, estando dentro dos valores de referência para a espécie. Variações além desta faixa de segurança e alterações na velocidade de acidificação da carne resultam em alterações expressivas na qualidade da carne, afetando a capacidade de retenção de água, maciez, rendimento tecnológico da carne, bem como a resistência ao ataque microbiano.

A capacidade de retenção de água é determinada pela quantidade de água perdida por meio de aplicação de força externa, como corte, aquecimento, trituração ou prensagem do tecido muscular. A menor capacidade de retenção de água da carne ovina implicará em perdas do valor nutritivo pelo exsudato liberado, além de resultar em carnes mais secas e com menor maciez ${ }^{(1)}$.

De maneira similar, as perdas por cocção são as perdas que ocorrem durante o processo de preparo da carne para o consumo, estando altamente correlacionadas com a capacidade de retenção de água, sendo esta altamente influenciada pelo $\mathrm{pH}$ da carne ${ }^{(39)}$. $\mathrm{O}$ fato de o $\mathrm{pH}$ não ter sido afetado pelas diferentes dietas, provavelmente contribuiu para os valores semelhantes de perdas por pressão e na cocção, bem como na perda por descongelamento.

Houve diferença $(\mathrm{P}<0,05)$ para o parâmetro de $\mathrm{FC}$, em que se observou efeito quadrático $\left(\hat{Y}=2,89+0,01973 x-0,00019 x^{2}, R^{2}=0,64\right)$. Segundo Monte et al. ${ }^{(1)}$, diversos fatores podem influenciar a FC, como, por exemplo: manejo pré-abate, velocidade de instalação do rigor mortis, pH no post mortem, temperatura pré-abate, instalação e extensão da glicólise, condições de acondicionamento e metodologia para as determinações, tais como: temperatura e tempo empregado no processo de cocção.

Pinheiro et al. ${ }^{(40)}$ também relataram que valores maiores ou menores para força de cisalhamento da carne ovina podem existir em função de interações entre diferentes taxas de deposição de colágeno e de gordura entremeada no músculo. $\mathrm{O}$ fator individual pode ter contribuído para esta diferença estatística, uma vez que não foi encontrada diferença significativa em nenhum outro parâmetro estudado, e os animais foram abatidos passando pelas mesmas condições de manejo pré-abate, bem como a metodologia utilizada foi a mesma para todos os animais.

De acordo com a classificação da maciez, citada por Boleman et al. ${ }^{(41)}$, em que valores de 2,3 a 3,6 correspondem a uma carne muito macia, 4,1 a 5,4 moderadamente macia, e 5,9 a 7,2 pouco macia, a carne deste estudo pode ser classificada como muito macia, com os valores médios contidos entre 2,79 e 3,53 .

Para os parâmetros de cor, os valores médios encontrados para os componentes $\mathrm{L}^{*}, \mathrm{a}^{*}$ e $\mathrm{b}^{*}$ foram de 40,32, 15,10 e 10,39. Esses resultados se assemelham em partes aos encontrados por Madruga et al. ${ }^{(7)}$, em que foram obtidos os seguintes valores para $L^{*}, a^{*}$ e b*: 40,9, 13,41 e 9,55, respectivamente. Observa-se que a carne dos animais pertencentes a este trabalho apresentou-se pouco mais vermelha do que a carne obtida dos animais avaliados por Madruga et al. ${ }^{(7)}$, também de cordeiros Santa Inês terminados em confinamento. Bressan et al. ${ }^{(42)}$ encontraram valores de $\mathrm{L}^{*}, \mathrm{a}^{*} \mathrm{e} \mathrm{b}^{*}$ de 33 a 40,10 a 14 e 6,5 a 8,5, respectivamente, em cordeiros Santa Inês, caracterizando uma carne mais escura, menos vermelha e menos pálida do que as do presente estudo.

A genética, sistema de produção, nutrição, idade e o $\mathrm{pH}$ final da carne podem exercer efeito importante sobre os valores de $\mathrm{L}^{*}, \mathrm{a}^{*} \mathrm{e} \mathrm{b}^{*}$. Estes valores também tendem a modificar com o aumento do peso de abate, devido à maior musculosidade do animal. Com o desenvolvimento muscular, aumenta a quantidade de mioglobina presente, o depósito de gordura começa a ficar mais evidente e, consequentemente, diminui a quantidade de água do músculo. Como resultado, obtém-se menor intensidade luminosa ${ }^{(43)}$.

Dada a semelhança entre os valores de $L^{*}, a^{*}$ e b*, para a saturação da cor e tonalidade também não foram encontrados efeitos $(\mathrm{P}>0,05)$ das dietas experimentais.

Não foi observado efeito $(\mathrm{P}>0,05)$, das dietas sobre a composição centesimal da carne, apresentando 
teores médios de 75,56\% de umidade $20,06 \%$ de PB, $1,77 \%$ de gordura e $0,97 \%$ de matéria mineral (Tabela 5).

Tabela 5. Composição centesimal do músculo Longissimus dorsi de cordeiros recebendo dietas con diferentes teores de torta de soja em substituição ao farelo de soja

\begin{tabular}{|c|c|c|c|c|c|c|c|}
\hline \multirow{2}{*}{ Componente } & \multicolumn{5}{|c|}{ Teores de torta de soja (\%) } & \multirow[b]{2}{*}{$\mathbf{R}^{1}$} & \multirow[b]{2}{*}{$\mathrm{CV}^{2}(\%)$} \\
\hline & 0 & 25 & 50 & 75 & 100 & & \\
\hline Umidade (g/kg MN) & 754,5 & 754,0 & 756,3 & 757,6 & 755,2 & $\hat{\mathrm{Y}}=755,6$ & 1,07 \\
\hline $\mathrm{PB}^{3}(\mathrm{~g} / \mathrm{kg} \mathrm{MS})$ & 201,98 & 197,15 & 203,60 & 202,34 & 197,79 & $\hat{\mathrm{Y}}=200,57$ & 3,64 \\
\hline Gordura ( $\mathrm{g} / \mathrm{kg} \mathrm{MS}$ ) & 17,65 & 20,06 & 15,66 & 16,61 & 19,18 & $\hat{\mathrm{Y}}=17,7$ & 28,50 \\
\hline $\mathrm{MM}^{4}(\mathrm{~g} / \mathrm{kg} \mathrm{MS})$ & 9,98 & 9,39 & 9,71 & 9,65 & 9,70 & $\hat{\mathrm{Y}}=9,70$ & 8,97 \\
\hline
\end{tabular}

${ }^{1}$ Regressão; ${ }^{2}$ Coeficiente de variação; ${ }^{3}$ Proteina bruta; ${ }^{4}$ Matéria mineral. $\mathrm{P}>0,05$.

Segundo Zeola et al. ${ }^{(44)}$, a composição média da carne ovina é $75 \%$ de umidade, $19 \%$ de PB, 4\% de gordura e $1,1 \%$ de matéria mineral, podendo variar de acordo com o grau de acabamento dos animais, aumentando a gordura em detrimento da proteína em animais mais velhos. No presente estudo, o fato de os animais serem da raça Santa Inês, caracterizada por ser uma raça de maturação relativamente tardia, pode ter levado ao um menor teor de gordura, ao passo que se observa um maior teor proteico.

Para a análise sensorial, foi encontrado efeito significativo $(\mathrm{P}<0,05)$, sendo que os animais recebendo a dieta com substituição total do farelo pela torta de soja apresentaram odor menos intenso, com valor de 2,62, caracterizando um efeito linear decrescente para este parâmetro $(\hat{\mathrm{Y}}=3,50-0,01 \mathrm{x})$. Para maciez, suculência e aceitabilidade global, não foram encontradas diferenças $(\mathrm{P}>0,05)$ (Tabela 6).

Tabela 6. Parâmetros de avaliação sensorial do músculo Longissimus dorsi de cordeiros recebendo dietas com diferentes teores de torta de soja em substituição ao farelo de soja

\begin{tabular}{lcccccc}
\hline \multirow{2}{*}{\multicolumn{1}{c}{ Variável }} & \multicolumn{3}{c}{ Teores de torta de soja (\%) } & & \\
\cline { 2 - 4 } & $\mathbf{0}$ & $\mathbf{5 0}$ & $\mathbf{1 0 0}$ & & $\mathbf{R}^{\mathbf{1}}$ & CV $^{\mathbf{2}}$ (\%) \\
\hline Intensidade do odor $^{4}$ & 3,62 & 2,75 & 2,62 & $\hat{\mathrm{Y}}^{3}$ & 26,48 \\
Maciez $^{5}$ & 4,62 & 5,12 & 5,25 & $\hat{\mathrm{Y}}=5,00$ & 31,55 \\
Suculência $^{6}$ & 3,25 & 3,12 & 3,87 & $\hat{\mathrm{Y}}=3,42$ & 29,44 \\
Aceitabilidade global $^{7}$ & 5,75 & 6,12 & 6,75 & $\hat{\mathrm{Y}}=6,21$ & 22,74 \\
\hline
\end{tabular}

${ }^{1}$ Regressão; ${ }^{2}$ Coeficiente de Variação; ${ }^{3} \hat{Y}=3,50-0,01 \mathrm{x} ; \mathrm{R}^{2}=0,84(\mathrm{P}<0,05) ;{ }^{4} 1$-nenhum odor a 5 -odor extremamente intenso; ${ }^{5} 1$-muito dura a 7 -muito macia; ${ }^{6} 1$-nenhuma suculência a 5 -alta suculência; ${ }^{7} 1$-extremamente inaceitável a 9 extremamente aceitável.

Os atributos sensoriais médios da carne, seguindo a escala estruturada utilizada, foram: odor ligeiro a moderado, maciez intermediária a pouco macia, suculência pouca a moderada e aceitabilidade global ligeiramente aceitável a moderada. Observa-se que, apesar dos resultados da FC caracterizarem a carne como muito macia, a análise sensorial caracterizou a carne como pouco macia a maciez intermediária, denotando a subjetividade da análise sensorial e ilustrando a importância da realização de ambas as análises.

Em relação à intensidade do odor, a causa exata que resulta no odor ovino desagradável ao consumidor, ainda não é bem conhecida. Acredita-se que ocorre devido à alta porcentagem de ácidos graxos saturados, além da degradação e reações de compostos solúveis em água durante o cozimento ${ }^{(45)}$. De acordo com Madruga et al. ${ }^{(7)}$, carnes com maior teor de gordura tendem a apresentar odor ovino mais intenso. O motivo ainda não é conhecido, porém é provável que seja devido ao perfil de ácidos graxos. 
Mottran $^{(46)}$ relata que o aroma ovino é resultante principalmente pelos ácidos graxos de cadeia ramificada, oriundos da biohidrogenação no rúmen. Dietas ricas em concentrado tendem a resultar em maior concentração de ácidos graxos de cadeia ramificada. Dentre esses ácidos graxos de cadeia ramificada, Sutherland e Ames ${ }^{(47)}$ relatam que o ácido 4-metil octanóico provavelmente é o responsável pelo odor sexual em ovinos.

Os teores de gordura encontrados na análise centesimal e na composição tecidual da paleta foram semelhantes, assim como o peso vivo final, estando este parâmetro relacionado à maturidade sexual dos animais. Portanto, o resultado esperado para o parâmetro de intensidade de odor era de semelhança entre as diferentes rações, ou de odor mais intenso nos animais com maior teor de torta de soja na dieta. Neste caso, o maior consumo de ácidos graxos insaturados, o que viria acompanhado de uma maior taxa de biohidrogenação, resultaria em maior concentração de ácidos graxos saturados, como o 4-metil octanóico, provável responsável pelo odor ovino. Entretanto, as reações que ocorreram no rúmen podem ter levado a uma concentração final de ácidos graxos de cadeia ramificada na gordura superior nos tratamentos com menor teor de torta de soja, resultando no efeito linear decrescente observado no presente estudo.

\section{Conclusões}

A substituição do farelo de soja pela torta de soja pode ser realizada sem influenciar a maioria das características da carcaça e da carne, podendo inclusive trazer benefício à qualidade sensorial da carne.

\section{Agradecimentos}

Os autores agradecem ao CNPq e CAPES pelo suporte financeiro.

\section{Referências}

1. Monte ALS, Gonsalves HRO, Villaroel ABS, Damaceno MN, Cavalcante ABD. Qualidade da carne de caprinos e ovinos: uma revisão [Quality of goats and lambs meat: a review]. Agropecuária Científica do SemiÁrido [Internet]. 2012 [cited 2014 May 28];8(3):11-17. Available from: http://150.165.111.246/ojs-patos/ index.php/ACSA/article/view/161/pdf

2. Barros CS, Monteiro ALG, Poli CHEC, Dittrich JR, Canziani JRF, Fernandes MAM. Rentabilidade da produção de ovinos em pastagem e em confinamento [Economic return of sheep production on pasture and in feedlot]. Revista Brasileira de Zootecnia [Internet]. 2009 [cited 2014 May 28]; 38(11):2270-2279. Available from: www.scielo.br/pdf/rbz/v38n11/a29v3811.pdf

3. Mota CJA, Pestana CFM. Co-produtos da produção de biodiesel [Co-products from biodiesel production]. Revista Virtual de Química [Internet]. 2011 [cited 2014 May 28]; 3(5):416-425. Available from: www.uff.br/ RVQ/index.php/rvq/article/viewFile/197/189

4. Brasil. Ministério de Minas e Energia. Agência Nacional do Petróleo, Gás Natural e Biocombustíveis. Boletim mensal de Biodiesel [Internet]. Brasília: ANP, 2014 [cited 2014 May 29]. Available from:

http://ubrabio.com.br/sites/1800/1891/PDFs/InformacaoSetor2014/BolBiodieselANPAbr2014.pdf

5. Santos VC, Ezequiel JMC, Morgado ES, Fávaro VR, D’Áurea AP, Sousa Junior SC. Desempenho e digestibilidade de componentes nutritivos de dietas contendo subprodutos de oleaginosas na alimentação de cordeiros [Performance and digestibility of nutritional components of diets containing byproducts of oleaginous in lambs feeding]. Semina: Ciências Agrárias [Internet]. 2014 [cited 2016 May 5];35(3):1577-1586. Available 
from: http://www.uel.br/revistas/uel/index.php/semagrarias/article/view/13692/14560

6. Soares BC, Souza KDS, Lourenço Junior JB. Desempenho e características de carcaça de cordeiros suplementados com diferentes níveis de resíduo do biodiesel [Performance and chacarcteristics of lamb carcass supplemented with different levels of biodiesel residues]. Arquivo Brasileiro de Medicina Veterinária e Zootecnia [Internet]. 2012 [cited 2014 Jun 1];64(6):1747-1754. Available from: http://dx.doi.org/10.1590/ $\underline{\text { S0102-09352012000600046 }}$

7. Madruga MS, Sousa WH, Rosales MD, Cunha MGG, Ramos JLF. Qualidade da carne de cordeiros Santa Inês terminados em diferentes dietas [Quality of Santa Ines lamb meat terminated with different diets]. Revista Brasileira de Zootecnia [Internet]. 2005 [cited 2014 Jun 1];34(1):309-315. Availabe from: www.scielo.br/pdf/ $\underline{\mathrm{rbz} / \mathrm{v} 34 \mathrm{n} 1 / 24544 . \mathrm{pdf}}$

8. Silva NV, Silva JHV, Coelho MS, Oliveira ERA, Araújo JA, Amâncio ALL. Características de carcaça e carne ovina: uma abordagem das variáveis metodológicas e fatores de influência [Characteristics of sheep carcass and mead: a review of methodology and factors of influence]. Acta Veterinaria Brasilica [Internet]. 2009 [cited 2014 Jun 1];2(4):103-110. Available from: http://periodicos.ufersa.edu.br/revistas/index.php/acta/ article/view/801

9. National Research Council. Nutrient requirements of sheep, 6th ed. Washington: National Academy Press; 1985. 99p.

10. Silva DJ, Queiroz AC. Análise de alimentos: métodos químicos e biológicos. 3rd ed. Viçosa: Imprensa Universitária da UFV; 2002. 235p. Portuguese.

11. Detmann E, Souza MA, Valadares Filho SC, Queiroz AC, Berchielli TT, Saliba EOS, Cabral LS, Pina DS, Ladeira MM, Azevedo JAG. Métodos para análise de alimentos. $1^{\text {st }}$ ed. Visconde do Rio Branco: Suprema; 2012. 214p. Portuguese.

12. Kearl LC. Nutrient requirements of ruminant in developing countries. 1st ed. Logan: Utah State University; 1982.381p.

13. Osório JCS, Osório MTM. Produção de carne ovina: técnicas de avaliação "in vivo" e na carcaça. 2nd ed. Pelotas: Editora Universitária; 2005. 82p. Portuguese.

14. American Meat Science Association. Meat evaluation handbook. 1st ed. Savoy: American Meat Science Association; 2001. 161p.

15. Fisher AV, De Boer H. The EAAP standard method of sheep carcass assessment. Livestock Production Science [Internet]. 1994 [cited 2014 Jun 4];38(3):149-159. Available from: http://www.sciencedirect.com/ science/article/pii/030162269490166X

16. Whipple G, Koohmaraie M, Dikeman ME, Crouse JD. Predicting beef-longissimus tenderness from various biochemical and histological muscle traits. Journal of Animal Science [Internet]. 1990 [cited 2014 Jun 4];68(12):4193-4199. Available from: http://www.journalofanimalscience.org/content/68/12/4193.long

17. Barbut S. Estimates and detection of the PSE problem in Young turkey breastmeat. Canadian Journal of Animal Science [Internet]. 1996 [cited 2014 Jun 4];76(1):455-457. Available from: dx.doi.org/10.4141\%2Fcjas96-066

18. Association of Official Analytical Chemists. Official methods of analysis of the Association of Official Analytical Chemists. 15th ed. Washington: Association of Official Analytical Chemists; 1990.

19. Associação Brasileira de Normas Técnicas. NBR 12994: Métodos de Análise Sensorial dos alimentos e bebidas. Rio de Janeiro;1993. 2p.

20. Cartaxo FQ, Cezar MF, Sousa WH, Gonzaga Neto S, Pereira Filho JM, Cunha MGG. Características 
quantitativas da carcaça de cordeiros terminados em confinamento e abatidos em diferentes condições corporais [Quantitative traits of carcass from lambs finished in feedlot system and slaughtered at different body conditions]. Revista Brasileira de Zootecnia [Internet]. 2009 [cited 2014 Jun 5];38(4):697-704. Available from: http://dx.doi.org/10.1590/S1516-35982009000400016

21. Urano FS, Pires AV, Susin I. Desempenho e características de carcaça de cordeiros alimentados com grãos de soja [Performance and carcass characteristics of feedlot lambs fed raw soybean]. Pesquisa Agropecuária Brasileira [Internet]. 2006 [cited 2014 Jun 5];41(10):1525-1530. Available from: http://dx.doi.org/10.1590/ $\underline{\mathrm{S} 0100-204 \mathrm{X} 2006001000010}$

22. Macedo VP, Silveira AC, Garcia CA, Monteiro ALG, Macedo FAF, Spers RC. Desempenho e características de carcaça de cordeiros alimentados em comedouros privativos recebendo rações contendo semente de girassol [Performance and carcass traits of lambs fed diets containing sunflower seed in creep feeding]. Revista Brasileira de Zootecnia [Internet]. 2008 [cited 2014 Jun 5];37(11):2041-2048. Available from: http://dx.doi. org/10.1590/S1516-35982008001100021

23. Silva Sobrinho AG, Purchas RW, Kadim IT, Yamamoto SM. Características de qualidade da carne de ovinos de diferentes genótipos e idades ao abate [Meat quality in lambs of different genotypes and ages at slaughter]. Revista Brasileira de Zootecnia [Internet]. 2005 [cited 2014 Jun 6];34(3):1070-1078. Available from: http://www.scielo.br/pdf/rbz/v34n3/a40v34n3.pdf

24. Furusho-Garcia IF, Perez JRO, Bonagurio S, Lima AL, Quintão FA. Estudo dos cortes de carcaça de cordeiros Santa Inês puros e cruzas Santa Inês com Texel, Ile de France e Bergamácia [Study of carcass cuts of Santa Ines and crosses with Texel, Ile de France and Bergamacia lambs]. Revista Brasileira de Zootecnia [Internet]. 2004 [cited 2014 Jun 6];33(2):453-462. Available from: http://dx.doi.org/10.1590/S1516-35982004000200024

25. Carvalho S, Brochier MA, Pivato J, Teixeira RC, Kieling R. Ganho de peso, características da carcaça e componentes não carcaça de cordeiros da raça Texel terminando em diferentes sistemas alimentares [Weight gain, carcass characteristics and non carcass components of lambs of breed Texel finished in different feeding systems]. Ciência Rural [Internet]. 2007 [cited 2014 Jun 6];37(3):821-827. Available from:http://dx.doi. org/10.1590/S0103-84782007000300034

26. Fernandes Junior F, Ribeiro ELA, Mizubuti IY, Silva LDF, Barbosa MAAF, Prado OPP, Pereira ES, Pimentel PG, Constantino C. Características de carcaça e qualidade da carne de cordeiros Santa Inês alimentados com torta de girassol em substituição ao farelo de algodão [Carcass characteristics and meat quality of Santa Ines lambs fed with sunflower cake replacing cottonseed meal]. Semina: Ciências Agrárias [Internet]. 2013 [cited 2014 Jun 6];34(6):3999-4014. Available from: http://dx.doi.org/10.5433/1679-0359.2013v34n6Supl2p3999

27. Cunha MGG, Carvalo FFR, Gonzaga Neto S, Cezar MF. Características quantitativas de carcaça de ovinos Santa Inês confinados alimentados com rações contendo diferentes níveis de caroço de algodão integral [Effect of feeding whole conttonseed levels on carcass quantitative characteristics of feedlot Santa Inez sheep]. Revista Brasileira de Zootecnia [Internet]. 2008 [cited 2016 May 5];37(6):1112-1120. Available from: http://www.sbz. org.br/revista/artigos/7034.pdf

28. Ribeiro ELA, Oliveira HC, Castro FAB, Mizubuti IY, Silva LDF, Barbosa MAAF. Características de carcaça e carne de cordeiros mestiços de três grupos genéticos [Carcass and meat characteristics of crossbred lambs from three genetic groups. Semina: Ciências Agrárias [Internet]. 2010 [cited 2014 Jun 6];31(3):793-802. Available from: http://www.uel.br/revistas/uel/index.php/semagrarias/article/viewFile/2011/5937

29. Boccard R, Dumont BL. Etude de la production de la viande chez les ovins. Il variation de l'importance relative des differents régions corporelles de l'agneau de boucherie. Annales de Zootechnie [Internet]. 1960 [cited 2014 Jun 6];9(4):355-365. Available from: http://hal.archives-ouvertes.fr/docs/00/88/67/36/PDF/hal$\underline{00886736 . p d f}$

30. Simela L, Ndlovu RL, Sibanda LM. Carcass characteristics of the marketed Matebele goat from south- 
western Zimbabwe. Small Ruminant Research [Online]. 1999 [cited 2014 Jun 6];32(2):173-179. Available from: http://dx.doi.org/10.1016/S0921-4488(98)00182-5

31. Zundt M, Macedo FAF, Astolphi JLL, Mexia AA, Sakaguti ES. Desempenho e características de carcaça de cordeiros Santa Inês confinados, filhos de ovelhas submetidas à suplementação alimentar durante a gestação [Production and carcass characteristic of confined lambs born from Santa Inês ewes supplemented in different stages of pregnancy]. Revista Brasileira de Zootecnia [Internet]. 2006 [cited 2014 Jun 7];35(3):928-935. Available from: http://dx.doi.org/10.1590/S1516-35982006000300040

32. Rosa GT, Pires CC, Silva JHS, Motta OS, Colomé LM. Composição tecidual da carcaça e de seus cortes e crescimento alométrico do osso, músculo e gordura da carcaça de cordeiros da raça Texel [The carcass tissue composition and its cuts, and bone, muscle and fat allometric growth of texel lambs]. Acta Scientiarum. Animal Sciences [Internet]. 2002 [cited 2014 Jun 7];24(4):1107-1111. Available from: http://eduem.uem.br/ ojs/index.php/ActaSciAnimSci/article/viewFile/2534/1753

33. Garcia CA, Monteiro ALG, Costa C, Neres MA, Rosa GJM. Medidas Objetivas e Composição Tecidual da Carcaça de Cordeiros Alimentados com Diferentes Níveis de Energia em Creep Feeding [Objective measurements and tissue composition of carcass of lambs fed with different energy levels in creep feeding]. Revista Brasileira de Zootecnia [Internet]. 2003 [cited 2014 Jun 7];32(6):1380-1390. Available from:http:// dx.doi.org/10.1590/S1516-35982003000600013

34. Santos JRS, Pereira Filho JM, Azevêdo AM. Composição tecidual e química dos cortes comerciais da carcaça de cordeiros Santa Inês terminados em pastagem nativa com suplementação [Tissue and chemical composition of commercial cuts of carcasses of Santa Ines lambs finished in native pasture with different supplementation levels]. Revista Brasileira de Zootecnia [Internet]. 2009 [cited 2014 Jun 7];38(12):24992505. Available from: http://dx.doi.org/10.1590/S1516-35982009001200028

35. Cartaxo FQ, Sousa WH. Correlações entre as características obtidas in vivo por ultra-som e as obtidas na carcaça de cordeiros terminados em confinamento [Correlations between tratis obtained by real time ultrasound and those obtained in the carcass of feedlot finished lambs]. Revista Brasileira de Zootecnia [Internet]. 2008 [cited 2016 May 5];37(8):1490-1495. Available from: http://dx.doi.org/10.1590/S1516-35982008000800022

36. Araújo JF, Landim AV, Cardoso MTM, Pimentel CM, Louvandini H, Vasconcelos AM, Carvalho RA. Área de olho de lombo e espessura de gordura da $12^{\text {a }}$ costela de ovinos de diferentes grupos genéticos e pesos de abate [Internet]. Brasília: Associação Brasileira de Zootecnia; 2009 Aug 25 [cited 2014 Jun 7]. Available from: http://www.abz.org.br/publicacoes-tecnicas/anais-zootec/artigos-cientificos/reproducao-melhoramentoanimal/21589-rea-olho-lombo-espessura-gordura-costela-ovinos-diferentes-grupos-genticos-pesos-abate1.

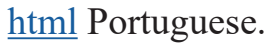

37. Cartaxo FQ, Souza VH, Cezar MF, Costa RG, Cunha MGG, Gonzaga Neto S. Características de carcaça determinadas por ultrassonografia em tempo real e pós-abate de cordeiros terminados em confinamento com diferentes níveis de energia na dieta [Carcass traits determined by ultrassonography in real time and after slaughter of lambs finished in feedlot with different levels of energy in the diet]. Revista Brasileira de Zootecnia [Internet]. 2011 [cited 2014 Jun 7];40(1):160-167. Available from: www.scielo.br/pdf/rbz/v40n1/v40n1a23

38. Sousa WH, Cartaxo FQ, Ojeda MDB, Cunha MGG, Cezar MF, Souza Junior EL, Cabral HB, Viana JA. Desempenho, características morfométricas e de carcaça de ovinos e caprinos submetidos a provas zootécnicas [Performance, morphometric and carcass tratis of sheep and goat submitted to performance test]. Tecnologia \& Ciência Agropecuária [Internet]. 2011 [cited 2014 Jun 7];5(3):47-51. Available from: http://gestaounificada. pb.gov.br/emepa/publicacoes/revista-1/edicoes/volume-05-2011/volume-5-numero-3-setembro-2011/ tca5309.pdf

39. Zeola NMBL, Souza PA, Souza HBA, Silva Sobrinho AG, Barbosa JC. Cor, capacidade de retenção de água e maciez da carne de cordeiro maturada e injetada com cloreto de cálcio [Colour, water holding capacity and tenderness of lamb aged and injected with calcium chloride]. Arquivo Brasileiro de Medicina Veterinária 
e Zootecnia [Internet]. 2007 [cited 2014 Jun 8];59(4):1058-1066. Available from: http://dx.doi.org/10.1590/ $\underline{\text { S0102-09352007000400036 }}$

40. Pinheiro RSB, Jorge AM, Souza HBA, Boiago MM. Coloração da gordura e qualidade da carne de ovelhas de descarte abatidas em distintos estágios fisiológicos [Fat coloring and meat quality of culling ewes slaughtered at distinct physiological stages]. Arquivo Brasileiro de Medicina Veterinária e Zootecnia [Internet]. 2010 [cited 2014 Jun 8];62(2):468-474. Available from: http://dx.doi.org/10.1590/S0102-09352010000200029

41. Boleman SJ, Boleman SL, Miller RK, Taylor JF, Cross HR, Wheeler TL, Koohmaraie M, Shackelford SD, Miller MF, West RL, Johnson DD, Savell JW. Consumer evaluation of beef of known categories of tenderness. Journal of Animal Science [Internet]. 1997 [cited 2014 Jun 8];75(6):1521-1524. Available from:http://www. journalofanimalscience.org/content/75/6/1521.short

42. Bressan MC, Prado OV, Pérez JRO, Lemos ALSC, Bonagurio S. Efeito do peso de abate de cordeiros Santa Inês e Bergamácia sobre as características físico-químicas da carne [Effect of the slaughter weight on the physical-chemical characteristic of Bergamacia and Santa Ines lambs meat]. Ciência e Tecnologia de Alimentos [Internet]. 2001 [cited 2014 Jun 9];21(3):293-303. Available from:http://dx.doi.org/10.1590/S010120612001000300008

43. Bonagurio S, Pérez JRO, Furusho-Garcia IF, Bressan MC, Lemos ALSC. Qualidade da carne de cordeiros Santa Inês puros e mestiços com Texel abatidos com diferentes pesos [Quality of meat production of purebred Santa Inês and crossbred Texel x Santa Ines lambs at different slaughter weights]. Revista Brasileira de Zootecnia [Internet]. 2003 [cited 2014 Jun 9];32(6):1981-1991. Available from: http://dx.doi.org/10.1590/ $\underline{\text { S1516-35982003000800023 }}$

44. Zeola NMBL, Silva Sobrinho AG, Gonzaga Neto S, Marques CAT. Composição centesimal da carne de cordeiros submetidos a dietas com diferentes teores de concentrado [Centesimal composition of lamb meat submitted to diets with different concentrate levels]. Ciência Rural [Internet]. 2004 [cited 2014 Jun 10];34(1):253-257. Available from: http://dx.doi.org/10.1590/S0103-84782004000100039

45. Melton SL. Effects of feeds on flavor of red meat: a review. Journal of Animal Science [Internet]. 1990 [cited 2014 Jun 10];68(12):4421-4435. Available from: http://www.journalofanimalscience.org/content/68/12/4421. long

46. Mottran,DS. Flavour formation in meat and meat products: a review. Food Chemistry [Internet]. 1998 [cited 2014 Jun 10];62(4):415-424. Available from: http://www.sciencedirect.com/science/article/pii/ $\underline{\mathrm{S} 0308814698000764}$

47. Sutherland MM, Ames J.M. The effect of castration on the headspace aroma components of cooker lamb. Journal of the Science of Food and Agriculture [Internet]. 1995 [cited 2014 Jun 10];69(4):403-413. Available from: http://onlinelibrary.wiley.com/doi/10.1002/jsfa.2740690402/abstract 